\title{
Social Determinants of Health Correlating with Mechanical Ventilation of COVID-19 Patients: A Multi-Center Observational Study
}

\author{
Alexa Giovanatti ${ }^{1}$ \\ Heba Elassar ${ }^{2}$ \\ Patrick Karabon ${ }^{3}$ \\ Tracy Wunderlich-Barillas ${ }^{3}$ \\ Alexandra Halalau ${ }^{2}$ \\ 'Internal Medicine Department, \\ Beaumont Health, Royal Oak, MI, USA; \\ ${ }^{2}$ Internal Medicine Department, Oakland \\ University William Beaumont School of \\ Medicine, Rochester, MI, USA; ${ }^{3}$ Office of \\ Research, Oakland University William \\ Beaumont School of Medicine, Rochester, \\ MI, USA
}

Importance: Several studies have relayed the disproportionate impact of COVID-19 on marginalized communities; however, few have specifically examined the association between social determinants of health and mechanical ventilation (MV).

Objective: To determine which demographics impact MV rates among COVID-19 patients. Design: This observational study included COVID-19 patient data from eight hospitals' electronic medical records (EMR) between February 25, 2020, to December 31, 2020. Associations between demographic data and MV rates were evaluated using uni- and multivariate analyses.

Setting: Multicenter (eight hospitals), largest health system in Southeast Michigan.

Participants: Inpatients with a positive RT-PCR for SARS-CoV-2 on nasopharyngeal swab. Exclusion criteria were missing demographic data or non-permanent Michigan residents.

Exposure: Patients were divided into two groups: MV and non-MV.

Main Outcome and Measures: The primary outcome was MV rate per demographic. A multivariate model then predicted the odds of MV per demographic descriptor. Hypotheses were formulated prior to data collection.

Results: Among 11,304 COVID-19 inpatients investigated, 1621 (14.34\%) were MV, and $49.96 \%$ were male with a mean age of 63.37 years (17.79). Significant social determinants for MV included Black race (40.19\% MV vs 31.31\% non-MV, $\mathrm{p}<0.01)$, poverty $(14.60 \%$ vs. $13.21 \%, \mathrm{p}<0.01)$, and disability $(12.65 \%$ vs $9.14 \% ; \mathrm{p}<0.01)$. Black race (AOR 1.61 (CI 1.41-1.83; p<0.01)), median income (AOR 0.99 (CI 0.99-0.99; p<0.01)), disability (AOR 1.55 (CI 1.26, 1.90; $<<0.01$ )), and non-English-speaking status (AOR 1.26 (CI 1.05, 1.53)) had significantly higher odds of MV.

Conclusions and Relevance: Black race, low socioeconomic status, disability, and nonEnglish-speaking status were significant risk factors for MV from COVID-19. An urgent need remains for a pandemic response program that strategizes care for marginalized communities.

Keywords: COVID-19, disparities, mechanical ventilation, race, socioeconomic

\section{Plain Language Summary}

Social determinants of health are associated with an increased risk of COVID-19 morbidity and mortality. ${ }^{1-3}$ In this retrospective observational study, we further illustrate how low socioeconomic status, Black race, disability, and non-English-speaking status were associated with an increased rate of mechanical ventilation from COVID19. These demographic descriptors can be used to help stratify COVID-19 risk and treatment by health-care providers in the emergency room (ER) and inpatient setting.
Correspondence: Alexa Giovanatti Beaumont Health, 360I W 13 Mile Road, Royal Oak, Ml, 48073, USA

Tel +l 248-898-5000

Email alexa.giovanatti@beaumont.org 


\section{Introduction}

\section{Background/Rationale}

The COVID-19 pandemic has illuminated the disparities within our healthcare system. Obesity, diabetes, race, and poverty have emerged as risk factors for the hospitalization of COVID-19 patients. $^{1,2}$ For instance, Black and Hispanic patients are more likely to test positive for COVID-19 ${ }^{3}$. However, findings related to mechanical ventilation (MV) of COVID-19 patients have not been welldefined. ${ }^{4}$ Recent studies suggest race $^{5}$ and poverty ${ }^{2}$ are associated with increased risk for ICU admission from COVID-19, though other studies find this correlation to be inconsistent. ${ }^{1} \mathrm{MV}$ of COVID-19 patients is associated with a high mortality rate, ${ }^{6}$ so identifying demographic risk factors for MV will help stratify and optimize treatment for patients at risk.

\section{Objectives}

Our study aims to identify social determinants of health that predispose COVID-19 patients to MV within a multicenter Michigan hospital system.

\section{Methods}

\section{Study Design}

We conducted a retrospective observational study at the largest healthcare system (eight hospitals) in southeast Michigan from February 25, 2020, to December 31, 2020. The study was approved under expedited review by the Beaumont Health Institutional Review Board (IRB), \#2020-209. Patient consent was waived as the study design was retrospective. Data confidentiality and compliance with the Declaration of Helsinki was maintained. We included all inpatients who were diagnosed with SARS-CoV2 infection by a positive RT-PCR on nasopharyngeal swab. Patients for whom any demographic data were missing or who were not permanent Michigan residents were excluded from analysis. Zip code level data from the United States Census Bureau such as rate of unemployment/use of public transportation/percentage of food stamp use were used as proxies for economic and employment status as individual-level data was not available from the electronic medical record (EMR). The zip code level data was eventually matched with the individual patient level data. Examined variables include age, ethnicity, marital status, education level, employment, zip code, primary language, disabilities, type of insurance, body mass index (BMI), and established primary care provider
(PCP). Univariate and multivariate analyses were run using SAS 9.4 software to determine any MV correlates. $\mathrm{P}$ values of less than 0.05 were considered statistically significant.

\section{Results \\ Participants}

A total of 11,304 patient records were admitted with a diagnosis of COVID-19. Of these, 1621 (14.34\%) were MV.

\section{Descriptive Data}

Of the total sample population, 58.8\% identified as White or Caucasian, $32.6 \%$ as Black or African American, 10\% as Arab or Middle Eastern, and 3.1\% as Hispanic or Latino. Males represented $49.96 \%$ of the sample. Patients with disabilities comprised $9.7 \%$ of the sample population.

\section{Outcome Data}

Table 1 illustrates the characteristics of the study participants, grouped by need for MV. The mean age in years for patients who were MV was 65.73 (SD 13.73), and for those who were not MV 63.4 (SD 18.33). On average, patients requiring $\mathrm{MV}$ were older $(\mathrm{p}<0.01)$ and had a significantly higher BMI (33.27 versus 31.12 ; $\mathrm{p}<0.01)$. Males had $47 \%$ greater odds of MV than females (OR $1.47, \mathrm{p}<0.01$ ). Black patients had $47 \%$ greater odds of MV than White patients (OR 1.47, $\mathrm{p}<0.01$ ). Disabled patients had $73 \%$ greater odds of MV than full-time working patients (OR 1.73, $\mathrm{p}=0.001)$. Patients with Medicare had $25 \%$ greater odds of MV than patients with private insurance (OR 1.25, $\mathrm{p}<0.01$ ), and those without a PCP had 14\% greater odds of MV than patients with a PCP (OR 1.14, $\mathrm{p}=0.03$ ). Patients needing MV were identified as living in zip codes associated with higher unemployment rates $(\mathrm{p}<0.01)$, public transportation to work $(\mathrm{p}<0.01)$, working in service professions $(\mathrm{p}<0.01)$, lower median income $(\mathrm{p}<0.01)$, and poverty $(\mathrm{p}<0.01)$.

\section{Main Results}

Table 2 illustrates a multivariate model to predict MV. For each additional year of age, odds of MV increased by $2 \%(\mathrm{p}<0.01)$. For each decrease of $\$ 1000$ in median income in a ZIP code, the adjusted odds of MV increased by $1 \%(p<0.01)$. Male gender (AOR 1.43, $\mathrm{p}<0.01$ ), Black race (AOR 1.61, p<0.01), low median income (AOR 0.99, $\mathrm{p}<0.01$ ), non-English 
Table I Descriptive Variables, Stratified by MV

\begin{tabular}{|c|c|c|c|c|}
\hline & Total & $M V(N=1621)$ & Non-MV (N = 9683) & p-value \\
\hline $\begin{array}{l}\text { Age of Patient (Years) }(n=11,304) \\
\text { Mean (Standard Deviation) }\end{array}$ & $63.77(17.79)$ & $65.73(13.73)$ & $63.40(18.33)$ & $<0.0001$ \\
\hline $\begin{array}{l}\text { Body Mass Index (BMI) }(n=10,916) \\
\text { Mean (Standard Deviation) }\end{array}$ & $31.43(8.75)$ & $33.27(9.05)$ & $31.12(8.51)$ & $<0.0001$ \\
\hline $\begin{array}{l}\text { Unemployment Rate of ZIP Code }(\%)(n=1|, 2| 2) \\
\text { Mean (Standard Deviation) }\end{array}$ & 7.44\% (4.78\%) & $8.00 \%(4.92 \%)$ & $7.35 \%(4.76 \%)$ & $<0.0001$ \\
\hline $\begin{array}{l}\text { Percent of ZIP Code Taking Public Transportation to Work }(\%)(n=||, 2 \mid 2) \\
\text { Mean (Standard Deviation) }\end{array}$ & $1.80 \%(2.72 \%)$ & $2.06 \%(2.93 \%)$ & $1.76 \%(2.68 \%)$ & 0.0001 \\
\hline $\begin{array}{l}\text { Percent of ZIP Code Working in White Collar Profession (\%) }(n=|1,2| 2) \\
\text { Mean (Standard Deviation) }\end{array}$ & $35.69 \%(13.87 \%)$ & $34.24 \%(13.23 \%)$ & $35.92 \%$ (13.96\%) & $<0.0001$ \\
\hline $\begin{array}{l}\text { Percent of ZIP Code Working in Service Profession }(\%)(n=|I, 2| 2) \\
\text { Mean (Standard Deviation) }\end{array}$ & $|8.4| \%(5.59 \%)$ & $18.99 \%$ (5.57\%) & $18.31 \%(5.59 \%)$ & $<0.0001$ \\
\hline $\begin{array}{l}\text { Median Income of ZIP Code }(\$)(\mathrm{n}=\mathrm{II}, 2 \mathrm{II}) \\
\text { Mean (Standard Deviation) }\end{array}$ & $\$ 60,704.80(\$ 25,539)$ & $\$ 57,068.40(\$ 23,179.14)$ & $\$ 61,311.67(\$ 25,871.93)$ & $<0.0001$ \\
\hline $\begin{array}{l}\text { Percent of ZIP Code on Food Stamps/SNAP* }(\%)(n=11,211) \\
\text { Mean (Standard Deviation) }\end{array}$ & $17.31 \%(13.27 \%)$ & $18.87 \%(13.48 \%)$ & $17.06 \%(13.23 \%)$ & $<0.0001$ \\
\hline $\begin{array}{l}\text { Poverty Rate of ZIP Code }(\%)(n=|1,2| 1) \\
\text { Mean (Standard Deviation) }\end{array}$ & $13.41 \%(10.82 \%)$ & $14.60 \%(10.97 \%)$ & $13.21 \%(10.79 \%)$ & $<0.0001$ \\
\hline $\begin{array}{l}\text { Biological Sex of Patient }(n=11,304) \\
\text { Female } \\
\text { Male }\end{array}$ & $\begin{array}{l}5657(50.04 \%) \\
5647(49.96 \%)\end{array}$ & $\begin{array}{l}678(41.85 \%) \\
942(58.15 \%)\end{array}$ & $\begin{array}{l}4970(51.38 \%) \\
4703(48.62 \%)\end{array}$ & $<0.0001$ \\
\hline $\begin{array}{l}\text { Race of Patient }(\mathrm{n}=11,304) \\
\text { American Indian or Alaska Native } \\
\text { Asian } \\
\text { Black or African American } \\
\text { Native American or Pacific Islander } \\
\text { Other } \\
\text { White or Caucasian } \\
\text { Unknown }\end{array}$ & $\begin{array}{r}34(0.30 \%) \\
230(2.03 \%) \\
3684(32.59 \%) \\
5(0.04 \% \\
699(6.18 \%) \\
6646(58.79 \%) \\
6(0.05 \%)\end{array}$ & $\begin{array}{r}5(0.31 \%) \\
32(1.98 \%) \\
651(40.19 \%) \\
1(0.06 \%) \\
84(5.19 \%) \\
846(52.22 \%) \\
1(0.06 \%)\end{array}$ & $\begin{array}{r}29(0.30 \%) \\
198(2.05 \%) \\
3029(31.31 \%) \\
4(0.04 \%) \\
613(6.34 \%) \\
5795(59.91 \%) \\
5(0.05 \%)\end{array}$ & $<0.0001$ \\
\hline $\begin{array}{l}\text { Ethnicity of Patient }(n=11,304) \\
\text { Arabic or Middle Eastern } \\
\text { Hispanic or Latino } \\
\text { Not Hispanic or Latino } \\
\text { Other } \\
\text { Unknown }\end{array}$ & $\begin{array}{r}1139(10.08 \%) \\
351(3.11 \%) \\
9273(82.03 \%) \\
440(3.89 \%) \\
101(0.89 \%\end{array}$ & $\begin{array}{r}157(9.69 \%) \\
59(3.64 \%) \\
1329(82.04 \%) \\
60(3.70 \%) \\
15(0.93 \%)\end{array}$ & $\begin{array}{r}982(10.15 \%) \\
292(3.02 \%) \\
7936(82.04 \%) \\
377(3.90 \%) \\
86(0.89 \%)\end{array}$ & 0.7024 \\
\hline $\begin{array}{l}\text { Marital Status }(n=11,304) \\
\text { Divorced } \\
\text { Married } \\
\text { Separated } \\
\text { Single } \\
\text { Widowed } \\
\text { Unknown }\end{array}$ & $\begin{array}{r}1114(9.85 \%) \\
5199(45.99 \%) \\
124(1.10 \%) \\
2967(26.25 \%) \\
1746(15.45 \%) \\
154(1.36 \%)\end{array}$ & $\begin{array}{r}179(11.05 \%) \\
761(46.98 \%) \\
14(0.86 \%) \\
445(27.47 \%) \\
189(11.67 \%) \\
32(1.98 \%)\end{array}$ & $\begin{array}{r}933(9.65 \%) \\
4437(45.87 \%) \\
110(1.14 \%) \\
2522(26.07 \%) \\
1550(16.02 \%) \\
121(1.25 \%)\end{array}$ & $<0.0001$ \\
\hline $\begin{array}{l}\text { English Language Speaker }(\mathrm{n}=11,304) \\
\text { Yes } \\
\text { No }\end{array}$ & $\begin{array}{r}10,082(89.19 \%) \\
1222(10.81 \%)\end{array}$ & $\begin{array}{r}1426(88.02 \%) \\
194(11.98 \%)\end{array}$ & $\begin{array}{l}8645(89.37 \%) \\
1028(10.63 \%)\end{array}$ & 0.1061 \\
\hline
\end{tabular}

(Continued) 
Table I (Continued).

\begin{tabular}{|c|c|c|c|c|}
\hline & Total & $M V(N=1621)$ & Non-MV $(N=9683)$ & p-value \\
\hline \multicolumn{5}{|c|}{ Employment Status $(\mathrm{n}=11,239)$} \\
\hline Disabled & $1089(9.68 \%)$ & $205(12.65 \%)$ & $884(9.14 \%)$ & $<0.0001$ \\
\hline Full Time & $2536(22.56 \%)$ & $300(18.52 \%)$ & $2236(23.12 \%)$ & \\
\hline Homemaker & $104(0.92 \%)$ & $15(0.93 \%)$ & $89(0.92 \%)$ & \\
\hline Not Employed & $2382(21.19 \%)$ & $321(19.81 \%)$ & $2061(21.31 \%)$ & \\
\hline Part Time & 331 (2.95\%) & $35(2.16 \%)$ & 296 (3.06\%) & \\
\hline Retired & 4279 (38.07\%) & $648(40.00 \%)$ & $3631(37.54 \%)$ & \\
\hline Self Employed & $191(1.70 \%)$ & $25(1.54 \%)$ & $166(1.72 \%)$ & \\
\hline Student & $17(0.151 \%)$ & $0(0.00 \%)$ & 17 (0.18\%) & \\
\hline Unknown & $310(2.76 \%)$ & 7I (4.38\%) & $293(3.03 \%)$ & \\
\hline \multicolumn{5}{|c|}{ Primary Payer $(n=11,304)$} \\
\hline Private Insurance & 6005 (53.12\%) & $793(48.95 \%)$ & $5210(53.86 \%)$ & 0.0005 \\
\hline Uninsured & $132(1.17 \%)$ & $12(0.74 \%)$ & $120(1.24 \%)$ & \\
\hline Medicaid & $382(3.38 \%)$ & $56(3.46 \%)$ & $326(3.37 \%)$ & \\
\hline Medicare & $4760(42.11)$ & 757 (46.73\%) & $3994(41.29 \%)$ & \\
\hline Tricare/VA & $25(0.22 \%)$ & $2(0.12 \%)$ & $23(0.24 \%)$ & \\
\hline \multicolumn{5}{|c|}{ Has Primary Care Physician $(P C P)(n=11,304)$} \\
\hline Yes & 8526 (75.42\%) & $1188(73.33 \%)$ & 7329 (75.77\%) & 0.0352 \\
\hline No & $2778(24.58 \%)$ & $432(26.67 \%)$ & 2344 (24.23\%) & \\
\hline
\end{tabular}

Abbreviation: SNAP, Supplemental Nutrition Assistance Program.

speakers (AOR 1.26, $\mathrm{p}=0.015$ ), and disability (AOR 1.55, $\mathrm{p}<0.01)$ correlated with higher odds of mechanical MV.

\section{Discussion}

\section{Key Results}

Our results suggest that several demographic factors are associated with an increased risk of MV in COVID-19 patients. Beginning with socioeconomic status, MV patients were more likely to live in zip codes with higher rates of unemployment, poverty, public transportation, food stamp use, and essential service jobs. COVID-19 burden has been similarly observed in regions scoring high on the Distressed Communities Index, including Detroit. ${ }^{7,8}$ Zhang et al further demonstrated that NYC neighborhoods with disadvantaged social conditions (low socioeconomic status, non-white, elderly) had higher mortality rates from COVID-19. ${ }^{9}$ Under conditions of crowded living, public transport, and frontline work, transmission is more likely. ${ }^{9}$ Financial insecurity and lack of insurance may also delay seeking medical care until advanced stages of infection..$^{10}$ Accordingly, we were surprised to find that patients under the "Not employed" category did not have a higher risk of MV. This could be a limitation of the EMR if employment history is not updated.

In terms of race, we found that Black patients were at $47 \%$ greater odds of being MV than White patients. In
Michigan, Black residents constitute $14.1 \%$ of the population, ${ }^{11} 7 \%$ of COVID-19 cases, yet $20.1 \%$ of COVID-19 deaths as of May 26, 2021. ${ }^{12}$ Similar observations between Black race and COVID-19 burden have been found after controlling for pre-existing comorbidities. ${ }^{10}$ It is possible that Black patients delay seeking medical attention as quickly as their White counterparts. ${ }^{10}$ Distrust in medical providers or financial barriers as previously discussed may play a role. ${ }^{10}$ Black Americans also comprise a disproportionate percentage of frontline jobs where risk of exposure is high, including nursing homes or skilled care facilities, courier services, and urban transportation. ${ }^{13}$

Patients with disabilities were also more likely to be MV from COVID-19. Intellectual and developmental disability (IDD) has previously been shown to be at greater risk for COVID-19 infection, however these results may be confounded by population density as samples resided in group homes or urban settings where transmission is greater. ${ }^{14}$ More research to illuminate morbidity/mortality outcomes in disabled patients with COVID-19 is needed. Our results are limited as "disability" in the EMR does not delineate physical, intellectual, or professional definition.

In the univariate analysis, no significant difference was found between MV and non-MV patients regarding nonEnglish speaking status $(p=0.1061)$. However, when 
Table 2 Multivariate Model to Predict MV

\begin{tabular}{|c|c|c|}
\hline & AOR $(95 \% \mathrm{Cl})$ & P-value \\
\hline Age of Patient & $1.02(1.01,1.02)$ & $<0.0001$ \\
\hline Percent of ZIP Code Working in Service Industry & $0.98(0.96,0.99)$ & 0.0107 \\
\hline Median Income of ZIP Code ( $\$ 1000$ USD) & $0.99(0.99,0.99)$ & $<0.0001$ \\
\hline \multicolumn{3}{|l|}{ Biological Sex of Patient } \\
\hline Male & $1.43(1.28,1.60)$ & $<0.0001$ \\
\hline Female & Reference Group & \\
\hline \multicolumn{3}{|l|}{ Race of Patient } \\
\hline American Indian or Alaska Native & $1.24(0.49,3.17)$ & 0.6505 \\
\hline Asian & $1.25(0.85,1.84)$ & 0.2529 \\
\hline Black or African American & $1.61(1.41,1.83)$ & $<0.0001$ \\
\hline Native American or Pacific Islander & $3.28(0.43,25.1)$ & 0.2527 \\
\hline Other & $0.86(0.67,1.11)$ & 0.2560 \\
\hline Unknown & $1.32(0.17,10.2)$ & 0.7898 \\
\hline White or Caucasian & Reference Group & \\
\hline \multicolumn{3}{|l|}{ Marital Status } \\
\hline Divorced & $1.05(0.87,1.26)$ & 0.6256 \\
\hline Separated & $0.69(0.39,1.21)$ & 0.1927 \\
\hline Single & $1.02(0.89,1.18)$ & 0.7519 \\
\hline Unknown & $1.33(0.87,2.02)$ & 0.1894 \\
\hline Widowed & $0.61(0.51,0.74)$ & $<0.0001$ \\
\hline Married & Reference Group & \\
\hline \multicolumn{3}{|l|}{ English Speaker } \\
\hline No & $1.26(1.05,1.53)$ & 0.0150 \\
\hline Yes & Reference Group & \\
\hline \multicolumn{3}{|l|}{ Employment Status } \\
\hline Disabled & $1.55(1.26,1.90)$ & $<0.0001$ \\
\hline Homemaker & $1.50(0.85,2.66)$ & 0.1639 \\
\hline Not Employed & $1.13(0.94,1.35)$ & 0.1858 \\
\hline Part Time & $1.03(0.71,1.50)$ & 0.8596 \\
\hline Retired & $1.07(0.89,1.28)$ & 0.4861 \\
\hline Self Employed & $1.08(0.70,1.68)$ & 0.7324 \\
\hline Student & $0.33(0.22,6.00)$ & 0.4527 \\
\hline Unknown & $1.52(1.12,2.05)$ & 0.0070 \\
\hline Full Time & Reference Group & \\
\hline
\end{tabular}

adjusted for all other variables in the multivariate analysis, the odds of intubation were significantly increased in nonEnglish speaking patients $(\mathrm{p}=0.015)$. Indeed, language barriers, even with the help of translation services, have been associated with less frequent COVID-19 testing and thus higher burden of infection. ${ }^{15}$

Application of the aforementioned findings could be considered when stratifying patient risk in an emergency room or inpatient setting. Prognostic calculators, such as COVID-Nolab, ${ }^{16}$ help predict patient outcomes in resource limited settings where diagnostic labs are delayed or unavailable, and adding a demographic component to these calculations could improve their accuracy. Social determinants of health, particularly elderly and socioeconomically vulnerable patients, have even been associated with COVID-19 subphenotypes that yield higher mortality rates. ${ }^{17}$ Our findings further support the need for health policy to protect these more vulnerable communities. ${ }^{17}$

Our study focuses on a southeast Michigan population with a primarily urban and suburban demographic, though results can be generalized to the population as similar findings have been observed nationally and internationally. Limitations of this study include retrospective nature as well as potential inaccuracies and missing data in the medical record.

\section{Conclusion}

Health-care disparities have negatively impacted patient outcomes during the COVID-19 pandemic. Our study shows how Black race, low socioeconomic status, nonEnglish-speaking status, and disability were all predictors for MV from COVID-19. These demographic predictors should help health providers stratify patient risk and disposition in the ER or inpatient setting. What remains is an urgent need to create a pandemic response program that strategizes prevention and care for communities historically oppressed by structural inequalities.

\section{Data Sharing Statement}

The data used to support the findings of this study are available from the corresponding author upon request.

\section{Ethics Approval}

The study was approved by the Beaumont Health Institutional Review Board. The study was approved under expedited review and the patient consent was waived as the study design was retrospective. Data confidentiality and compliance with the Declaration of Helsinki were maintained.

\section{Funding}

This research did not receive any specific funding.

\section{Disclosure}

The authors have no conflicts of interest regarding the publication of this paper.

\section{References}

1. Gu T, Mack JA, Salvatore M, et al. Characteristics Associated With Racial/Ethnic Disparities in COVID-19 Outcomes in an Academic Health Care System. JAMA Netw Open. 2020;3(10):e2025197. doi:10.1001/jamanetworkopen.2020.25197 
2. Muñoz-Price LS, Nattinger AB, Rivera F, et al. Racial disparities in incidence and outcomes among patients with COVID-19. JAMA Netw Open. 2020;3(9):e2021892. doi:10.1001/jamanetworkopen.2020.21892

3. Ogedegbe G, Ravenell J, Adhikari S, et al. Assessment of Racial/ Ethnic Disparities in Hospitalization and Mortality in Patients With COVID-19 in New York City. JAMA Netw Open. 2020;3(12): e2026881. doi:10.1001/jamanetworkopen.2020.26881

4. Yu L, Halalau A, Dalal B, et al. Machine learning methods to predict mechanical ventilation and mortality in patients with COVID-19. PLoS One. 2021;16(4):e0249285. doi:10.1371/journal. pone.0249285. PMID: 33793600; PMCID: PMC8016242.

5. Poulson M, Geary A, Annesi C, et al. National Disparities in COVID-19 Outcomes between Black and White Americans. $J$ Natl Med Assoc. 2021;113(2):125-132. doi:10.1016/j.jnma.2020.07.009

6. Auld SC, Caridi-Scheible M, Blum JM, et al. The Emory COVID-19 Quality and Clinical Research Collaborative. ICU and Ventilator Mortality Among Critically Ill Adults With Coronavirus Disease 2019. Crit Care Med. 2020;48(9):e799-e804. doi:10.1097/ CCM.0000000000004457. PMID: 32452888; PMCID: PMC7255393.

7. Hawkins RB, Charles EJ, Mehaffey JH. Socio-economic status and COVID-19-related cases and fatalities. Public Health. 2020;189:129-134. doi:10.1016/j.puhe.2020.09.016. Epub 2020 Oct 17. PMID: 33227595; PMCID: PMC7568122.

8. Sandhu A, Korzeniewski SJ, Polistico J, et al. Elevated COVID19 mortality risk in Detroit area hospitals among patients from census tracts with extreme socioeconomic vulnerability. EClinicalMedicine. 2021;34:100814. doi:10.1016/j.eclinm.2021.100814

9. Zhang Y, Khullar D, Wang F, et al. Socioeconomic variation in characteristics, outcomes, and healthcare utilization of COVID-19 patients in New York City. PLoS One. 2021;16(7):e0255171. doi:10.1371/journal.pone.0255171. PMID: 34324574; PMCID: PMC8321227.
10. Parpia AS, Martinez I, El-Sayed AM, et al. Racial disparities in COVID-19 mortality across Michigan, United States. EClinicalMedicine. 2021;33:100761. doi:10.1016/j.eclinm.2021.100761

11. Census Bureau US. QuickFacts: Michigan. Census Bureau QuickFacts; 2021. Available form: https://www.census.gov/quick facts/Mi. Accessed May 26, 2021.

12. Coronavirus - Michigan Data. Michigan.gov; 2021. Available form: https://www.michigan.gov/coronavirus/0,9753,7-406-98163 98173—,00.html. Accessed May 26, 2021.

13. Labor Force Statistics from the Current Population Survey. U.S. Bureau of Labor Statistics. Available form: https://www.bls.gov/cps/ cpsaat18.htm. Accessed May 26, 2021.

14. Landes SD, Turk MA. COVID-19 outcomes among people with intellectual and developmental disability in California: the importance of type of residence and skilled nursing care needs. Disabil Health J. 2021;14(2):101051. doi:10.1016/j.dhjo.2020.101051. Epub 2020 Dec 5. PMID: 33309535; PMCID: PMC7719000.

15. Kim HN, Lan KF, Nkyekyer E, et al. Assessment of Disparities in COVID-19 Testing and Infection Across Language Groups in Seattle, Washington. JAMA Netw Open. 2020;3(9):e2021213. doi:10.1001/ jamanetworkopen.2020.21213

16. Ebell MH, Cai X, Lennon R, et al. Development and Validation of the COVID-NoLab and COVID-SimpleLab Risk Scores for Prognosis in 6 US Health Systems. J Am Board Fam Med. 2021;34(Suppl):S127S135. doi:10.3122/jabfm.2021.S1.200464. PMID: 33622827; PMCID: PMC8343954.

17. Su C, Zhang Y, Flory JH, et al. Clinical subphenotypes in COVID-19: derivation, validation, prediction, temporal patterns, and interaction with social determinants of health. NPJ Digit Med. 2021;4(1):110. doi:10.1038/s41746-021-00481-w. PMID: 34262117; PMCID: PMC8280198.
International Journal of General Medicine

\section{Publish your work in this journal}

The International Journal of General Medicine is an international, peer-reviewed open-access journal that focuses on general and internal medicine, pathogenesis, epidemiology, diagnosis, monitoring and treatment protocols. The journal is characterized by the rapid reporting of reviews, original research and clinical studies

\section{Dovepress}

across all disease areas. The manuscript management system is completely online and includes a very quick and fair peer-review system, which is all easy to use. Visit http://www.dovepress.com/ testimonials.php to read real quotes from published authors. 